\title{
DÜBLIN
}

Technological University Dublin

ARROW@TU Dublin

\section{Apple Pomace as a Potential Ingredient for the Development of New Functional Foods}

\author{
Sofia Reis \\ Technological University Dublin, sofiafreis@gmail.com \\ Dilip K. Rai \\ Teagasc, Ashtown Food Research Centre \\ Nissreen Abu-Ghannam \\ Technological University Dublin, nissreen.abughannam@tudublin.ie
}

Follow this and additional works at: https://arrow.tudublin.ie/schfsehart

Part of the Food Chemistry Commons

\section{Recommended Citation}

Reis, S. F., Rai, D. K., Abu-Ghannam, N. (2014). Apple pomace as a potential ingredient for the development of new functional foods. International Journal of Food Science \& Technology. doi: 10.1111/ ijfs.12477

This Article is brought to you for free and open access by the School of Food Science and Environmental Health at ARROW@TU Dublin. It has been accepted for inclusion in Articles by an authorized administrator of ARROW@TU

Dublin. For more information, please contact

arrow.admin@tudublin.ie, aisling.coyne@tudublin.ie, gerard.connolly@tudublin.ie.

Funder: Food Institutional Research Measure (FIRM)

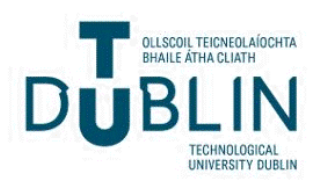




\title{
Original article
}

\section{Apple pomace as a potential ingredient for the development of new functional foods}

\author{
Sofia F. Reis, ${ }^{1}$ Dilip K. Rai ${ }^{2} \&$ Nissreen Abu-Ghannam ${ }^{1} *$ \\ 1 School of Food Science and Environmental Health, College of Sciences \& Health, Dublin Institute of Technology, Cathal Brugha St., \\ Dublin 1, Ireland \\ 2 Department of Food Biosciences, Teagasc Food Research Centre, Ashtown, Dublin 15, Ireland
}

(Received 17 July 2013; Accepted in revised form 26 November 2013)

\begin{abstract}
Summary Extruded snacks and baked scones were formulated with increasing levels $(0-30 \%)$ of apple pomace (AP). The incorporation of up to $20 \%$ of AP in extruded snacks and in baked scones does not change significantly $(P<0.05)$ the proximate composition of the final products, except for the content of starch of baked scones. At this level of incorporation, the fibre content, phenolic content and antioxidant capacity (DPPH radical scavenging activity, ferric reducing antioxidant power (FRAP) and $\beta$-carotene/linoleic acid system) increased when compared to the products to which no AP was added. Chlorogenic acid and quercetin were the major phenolic compounds found in the products. Loss of phenolic compounds during heat treatment occurred; however, the DPPH radical scavenging activity of final products was not affected.
\end{abstract}

Keywords Antioxidants, apple pomace, baking, dietary fibre, extrusion, LC-ESI/MS.

\section{Introduction}

Apple pomace (AP) is the main by-product of cider processing and pose a serious environmental problem due to the large amounts (millions of tonnes in EU alone) produced every year. AP is composed mainly of carbohydrates and dietary fibre, small amounts of protein, fat and ash (Wang \& Thomas, 1989; Carson et al., 1994; Sudha et al., 2007). AP is also a good source of phytochemicals primarily phenolic acids and flavonoids (Lu \& Foo, 2000; Schieber et al., 2003; SanchezRabaneda et al., 2004; Cetkovic et al., 2008; Diñeiro García et al., 2009). Some of the phenolic compounds identified in AP have been correlated with antioxidant capacities using various methods (DPPH, hydroxyl and superoxide anion radical scavenging activity, FRAP) and thereby confirming that the AP is a potential source of antioxidants (Lu \& Foo, 2000; Cetkovic et al., 2008; Diñeiro García et al., 2009). The common applications of this by-product are the direct disposal to soil in a landfill and for the recovery of pectins (gelling agent, stabiliser and source of dietary fibre). The very large volumes produced each year exceed existing uses and new applications for AP are required, and it may find use as a valuable food additive to the high levels of fibre and antioxidants it contains.

*Correspondent: E-mail: nissreen.abughannam@dit.ie
Functional foods reflect recent consumer interest in convenient food and healthy eating. The US Food and Drug Administration (FDA) suggests that functional foods are a food or food ingredients that may provide a health benefit beyond their nutritional content. Among the target compounds considered to be health benefiting for functional foods are dietary fibre and antioxidants (Goldberg, 1994). AP rich in fibre with significant amounts of antioxidants can be incorporated in human food-chain, thus generating new potential functional foods.

Extruded and baked snack products are predominantly made from cereal flour or starches and tend to be low in protein and thus with low nutritional value. The incorporation of enriched fibre flours with significant antioxidants is one way to improve the nutritional value of these snacks, which have been reflected in several previous studies using food by-products (Ainsworth et al., 2007; Stojceska et al., 2008a,b; Ajila et al., 2010). Apple by-products have been investigated as a source of dietary fibre in baked muffins and cookies (Wang \& Thomas, 1989) and also as a source of polyphenols in cakes (Sudha et al., 2007) and muffins (Rupasinghe et al., 2008). However, the few studies on baked products lack information regarding antioxidants and in addition, research on AP incorporation in extruded products has not been reported yet. In this study, we present 
the chemical composition and the antioxidant capacity of extruded and baked products that incorporate AP.

\section{Materials and methods}

\section{Chemicals}

All chemicals were purchased from Sigma-Aldrich (Arklow, Ireland) except for hydrochloric acid that was purchased from AlfaAesar (Karlsruhe, Germany), sodium citrate tribasic dehydrate from AnalaR NORMAPUR $^{\circledR}$ (VWR, Ballycoolin, Ireland) and sodium hydroxide from Applichem (Darmstadt, Germany). The solvents used for sample preparation for LC-MS studies were HPLC grade.

\section{Apple pomace}

Apple pomace (AP) was provided by Bulmers Limited (Clonmel, Ireland). On arrival, the samples were packed under vacuum to prevent oxidation and fermentation and stored at $-20{ }^{\circ} \mathrm{C}$ until being freezedried. The freeze-dried AP was coarsely ground and passed through $250 \mu \mathrm{m}$ sieve and stored in polyethylene bags at $-20{ }^{\circ} \mathrm{C}$.

\section{Incorporation in extruded products}

Extruded products were prepared from blends of rice flour and wheat semolina in a ratio of $(2: 1)$ with different proportions $(0,10,20$ and $30 \%)$ of AP on a dry weight basis. The samples were then conditioned to $15-20 \%$ moisture by spraying with a calculated amount of water and were mixed continuously at medium speed in a mixer (Hobart Mixer, Model F-50; HOBART, Troy, OH, USA), followed by storage at $4{ }^{\circ} \mathrm{C}$ overnight. Extrusion was performed in a singlescrew, laboratory model extruder (Brabender, Duisburg, Germany) with a DCE 330 attachment consisting of three independent zones of controlled temperature in the barrel. The screw speed used was $60 \mathrm{rpm}$ and the length to diameter (L:D) ratio for the extruder was 20:1. The temperature profiles in the feed and compression metering zones were kept constant at 110 and $150^{\circ} \mathrm{C}$, respectively, and the die head temperature was $190{ }^{\circ} \mathrm{C}$. After stable conditions were established, the extrudates were collected and dried in air oven at $60{ }^{\circ} \mathrm{C}$ for $1 \mathrm{~h}$. Extruded material was coarsely ground and passed through $250 \mu \mathrm{m}$ sieve stored at $4{ }^{\circ} \mathrm{C}$ in polyethylene bags.

\section{Incorporation in baked products}

Baked products were formulated as scones with Odlums Cream flour (Odlum Group, Dublin, Ireland) composed of $11 \%$ protein, $13 \%$ fat, $3.1 \%$ fibre and $13 \%$ moisture. In addition to Odlums Cream flour, the formulation also included baking powder $(4.5 \%)$, salt $(0.25 \%)$, caster sugar $(6.0 \%)$, margarine $(17 \%)$, eggs medium (32\%) and milk (41\%). Odlums Cream flour was replaced with 10,20 and $30 \%$ of AP for the different incorporated products. Baking was performed at $220{ }^{\circ} \mathrm{C}$ for $16 \mathrm{~min}$. The baked products were coarsely ground and passed through $250 \mu \mathrm{m}$ sieve, freeze-dried and stored in polyethylene bags at $4{ }^{\circ} \mathrm{C}$ for further analysis.

\section{Chemical characterisation}

Moisture and ash contents were determined according to AOAC 925.10 and 923.03 methods, respectively. Fat was determined by weight difference after extraction of the sample with diethyl ether $(1: 20 ; \mathrm{w} / \mathrm{v})$ in a Soxhlet system for $8 \mathrm{~h}$ at $60^{\circ} \mathrm{C}$. Protein was determined as total nitrogen content $\left(\mathrm{N}^{*} 6.25\right)$ using the Kjeldahl method following the AOAC 920.87 method. Starch was determined by amyloglucosidase/ $\alpha$-amylase method using Megazyme analysis kit (Megazyme International Ltd, Bray, Ireland) based on AOAC 996.11 method. Total dietary fibre (TDF) was determined using a Sigma-Aldrich analysis kit based on AOAC 991.43 method. Protein and starch digestibility was determined according to methods previously described (Onyango et al., 2004). All measurements were carried out in triplicate.

\section{Extraction of phenolic compounds}

The extraction of phenolic compounds followed the method described previously by the same authors (Reis et al., 2012). Briefly, the freeze-dried and ground samples $(3 \mathrm{~g})$ were stirred with $40 \mathrm{~mL}$ of water three times $(40,40,10 \mathrm{~min})$ at room temperature. In each extraction, the water extracts were filtered and the three supernatants obtained were combined. Solid-phase extraction (SPE) with $\mathrm{C}_{18}$ cartridges (DSC-18; Supelco, Sigma-Aldrich) was performed to select the organic compounds from the crude extract and to remove the sugars from each extract, which will otherwise interfere with the Folin assay. The sugars were eluted from the SPE cartridges with $300 \mathrm{~mL}$ of $2 \%$ acetic acid and the phenolic-rich fraction was eluted with methanol containing $0.1 \% \mathrm{HCl}$. The phenolic-rich fraction was concentrated (by evaporation at $40{ }^{\circ} \mathrm{C}$ ), frozen $\left(-70{ }^{\circ} \mathrm{C}\right.$ ) and freeze-dried.

\section{Determination of phenolic compounds}

Total phenolic content (TPC), total flavonoid content (TFC) and proanthocyanidins content (PAC) were determined according to Reis et al. (2012). 


\section{Antioxidant capacity evaluation}

The antioxidant capacity was evaluated by the DPPH radical scavenging activity, ferric reducing antioxidant power (FRAP) and $\beta$-carotene/linoleic acid system (BCLAS) according to Reis et al. (2012).

\section{Liquid chromatography - electrospray ionisation mass spectrometry (LC-ESI/MS)}

LC-ESI/MS was performed on a Q-Tof Premier mass spectrometer (Waters Corp., Micromass MS Technologies, Manchester, UK) coupled to an Alliance 2695 HPLC system (Waters Corp., Milford, MA, USA) as described previously by Reis et al. (2012).

\section{Statistical analysis}

All TPC, TFC, PAC, DPPH, FRAP and BCLAS measurements were carried out in three independent extractions and performed in triplicate for each extraction. All data were reported as mean \pm standard deviation (SD). ANOVA one-way statistical analysis was carried out to determine significant differences between means. To assess which means were different from which means, Tukey's method was used as an additional test to ANOVA. Differences were considered to be statistically significant at $P \leq 0.05$.

\section{Results and discussion}

\section{Chemical characterisation}

The significant differences observed in extruded and baked products with AP incorporation were the decrease in protein and starch contents while the TDF increased (Table 1). The decrease in protein and starch can be attributed to the partial replacement of the flour mixture by AP, due to the flour mixture in both extruded and baked products is richer in protein and starch than AP. TDF of AP-incorporated extruded products increased 1.8 -fold with $30 \%$ AP incorporation. However, the recovery of TDF in final products was 0.64 for 10 and $30 \%$ AP addition and 0.76 for $20 \%$ AP addition (Table S1). It is likely that extrusion is promoting polymerisation reactions between polysaccharides and proteins or phenolic compounds as suggested by Onyango et al. (2004), Stojceska et al. (2008a) and Ajila et al. (2010) thus affecting the recovery of TDF. For $30 \%$ AP incorporation in baked products, a 2.3-fold increase was observed in TDF and total recovery was obtained for all levels of AP incorporation. Wang \& Thomas (1989) also observed 1.6-fold increase in TDF in moon cookies where the quickcooking oats used in the filling were substituted by $40 \%$ AP. Interestingly, Sudha et al. (2007) observed a substantially high (30-fold increase) TDF upon $25 \%$ AP incorporation in cakes. This high increase is probably due to variations in the size of the ground powder of AP used to mix in with the flour, because reducing particle size increases surface area thus enhancing nutrients extraction. Other possible causes for Sudha et al. (2007) result can also be due to differences in AP fibre composition and processing parameters used in the formulation of the baked products; however, as far as we know, it was never reported such a high difference due to these parameters.

In vitro soluble (IVSP) and insoluble (IVISP) protein digestibility in extruded products showed a significant decrease upon $20 \%$ incorporation of AP (Table 1). A reduction of $50 \%$ in IVSP and $57 \%$ in IVISP was observed with the incorporation of $30 \%$ of AP in comparison with the control sample $(0 \% \mathrm{AP})$. The low protein digestibility has been attributed to possible changes in the proteins during cooking such as the formation of enzyme-resistant complexes due to the interaction between the proteins and nonstarch polysaccharides, polyphenols, starch and antinutrients (Onyango et al., 2004; Stojceska et al., 2008a). It is possible that adding AP with high contents of dietary fibre and polyphenols has promoted the formation of complexes resistant to pepsin action as indicated earlier for the TDF recoveries. Baked products showed no significant differences for IVSP and IVISP between control and AP-incorporated products (Table 1). Nitrogen solubility index (NSI) indicates the level of protein solubility in water which gives an indication of the extent of protein denaturation (Onyango et al., 2004). In extruded products, NSI decreased significantly by $23 \%$ with the addition of $30 \%$ AP (Table 1). It implies that polymerisation, cross-linking and reorientation of the proteins to form new fibrous structures must have occurred as postulated by Onyango et al. (2004). In baked products, NSI results showed a significant increase of up to $16 \%$ with the addition of $30 \%$ AP (Table 1), indicating that protein denaturation has actually occurred. Starch digestibility showed a significant decrease upon the addition of $30 \%$ AP in extruded products; however, no significant changes were recorded for the additions of AP in baked products (data not shown).

The incorporation of AP in extruded and baked products does not compromise the nutritional value of the final products but improves it by increasing the overall fibre content. However, for the $30 \%$ AP incorporation in extruded products, the results indicate the formation of enzyme-resistant complexes, which contributes to up to $50 \%$ decrease in protein digestibility.

\section{Determination of phenolic compounds}

The incorporation of AP in extruded and baked products significantly increased TPC, TFC and PAC when 
Apple pomace ingredient for functional foods S. F. Reis et al.

Table 1 Proximate composition of AP, incorporated AP extruded and baked products and protein digestibility of incorporated AP products

\begin{tabular}{|c|c|c|c|c|c|c|c|c|c|}
\hline & Moisture \% & Ash \% & Fat $\%$ & Protein \% & Starch \% & TDF \% & IVSP \% & NSI \% & IVISP \% \\
\hline AP & $8 \pm 0.4$ & $1 \pm 0.2$ & $2 \pm 0.1$ & $3 \pm 0.1$ & $8 \pm 0.5$ & $42 \pm 1.4$ & - & - & - \\
\hline \multicolumn{10}{|c|}{ Extruded products } \\
\hline $0 \%$ & $8 \pm 0.01$ & $0.4 \pm 0.1$ & $\operatorname{tr}$ & $11 \pm 0.04$ & $72 \pm 5.4$ & $7 \pm 0.3$ & $71 \pm 3.1$ & $10 \pm 0.9$ & $67 \pm 3.6$ \\
\hline $10 \%$ & $8 \pm 0.1$ & $0.4 \pm 0.02$ & $0.1 \pm 0.02$ & $10 \pm 0.02$ & $70 \pm 2.2$ & $9 \pm 0.7$ & $60 \pm 6.8$ & $9 \pm 0.8$ & $55 \pm 7.8$ \\
\hline $20 \%$ & $6 \pm 0.1$ & $0.4 \pm 0.01$ & $0.2 \pm 0.02$ & $10 \pm 1.2$ & $63 \pm 1.3$ & $12 \pm 0.5$ & $51 \pm 9.0$ & $5 \pm 0.3$ & $47 \pm 9.3$ \\
\hline $30 \%$ & $6 \pm 0.1$ & $0.5 \pm 0.1$ & $0.2 \pm 0.02$ & $9 \pm 0.2$ & $56 \pm 0.8$ & $13 \pm 1.0$ & $35 \pm 3.5$ & $8 \pm 0.4$ & $29 \pm 5.2$ \\
\hline \multicolumn{10}{|c|}{ Baked products } \\
\hline $0 \%$ & $2 \pm 0.4$ & $3 \pm 0.03$ & $13 \pm 0.02$ & $14 \pm 1.8$ & $61 \pm 2.7$ & $8 \pm 0.05$ & $87 \pm 7.7$ & $11 \pm 2.3$ & $85 \pm 13$ \\
\hline $10 \%$ & $2 \pm 0.1$ & $3 \pm 0.02$ & $13 \pm 0.1$ & $12 \pm 0.02$ & $50 \pm 3.0$ & $12 \pm 0.1$ & $83 \pm 6.3$ & $12 \pm 0.3$ & $81 \pm 10$ \\
\hline $20 \%$ & $3 \pm 0.1$ & $3 \pm 0.2$ & $13 \pm 0.5$ & $12 \pm 0.2$ & $27 \pm 2.2$ & $15 \pm 0.1$ & $81 \pm 5.3$ & $13 \pm 1.1$ & $76 \pm 6.0$ \\
\hline $30 \%$ & $3 \pm 0.1$ & $3 \pm 0.1$ & $13 \pm 0.8$ & $11 \pm 0.2$ & $34 \pm 1.8$ & $18 \pm 0.2$ & $74 \pm 5.5$ & $13 \pm 0.2$ & $73 \pm 4.7$ \\
\hline
\end{tabular}

TDF, total dietary fibre; tr, traces; IVSP, in vitro soluble protein digestibility; NSI, nitrogen solubility index; IVISP, in vitro insoluble protein digestibility.

Table 2 Quantities of TPC, TFC, PAC, DPPH, FRAP and BCLAS expected and observed in incorporated AP extruded and baked products and their respective recoveries

\begin{tabular}{|c|c|c|c|c|c|c|c|c|c|}
\hline & \multicolumn{3}{|l|}{ TPC } & \multicolumn{3}{|l|}{ TFC } & \multicolumn{3}{|l|}{ PAC } \\
\hline & \multicolumn{2}{|c|}{$\mu \mathrm{g}$ gallic acid/g DW } & $\begin{array}{l}\text { Recovery } \\
\%\end{array}$ & \multicolumn{2}{|c|}{$\mu \mathrm{g}$ quercetin/g DW } & $\begin{array}{l}\text { Recovery } \\
\%\end{array}$ & \multicolumn{2}{|c|}{$\mu \mathrm{g}$ catechin/g DW } & $\begin{array}{l}\text { Recovery } \\
\%\end{array}$ \\
\hline \multicolumn{10}{|c|}{ Extruded products } \\
\hline $10 \%$ & 170 & 185 & 109 & 480 & 460 & 96 & 43 & 37 & 86 \\
\hline $20 \%$ & 340 & 287 & 84 & 960 & 487 & 51 & 86 & 26 & 30 \\
\hline $30 \%$ & 510 & 413 & 81 & 1440 & 671 & 47 & 129 & 53 & 41 \\
\hline \multicolumn{10}{|c|}{ Baked products } \\
\hline $10 \%$ & 170 & 90 & 53 & 480 & 278 & 58 & 43 & 7 & 17 \\
\hline $20 \%$ & 340 & 249 & 73 & 960 & 475 & 49 & 86 & 35 & 41 \\
\hline \multirow[t]{3}{*}{$30 \%$} & 510 & 274 & 54 & 1440 & 550 & 38 & 129 & 22 & 17 \\
\hline & \multicolumn{3}{|l|}{ DPPH } & \multicolumn{3}{|l|}{ FRAP } & \multicolumn{3}{|l|}{ BCLAS } \\
\hline & $\begin{array}{l}\text { Expected } \\
\% \text { inhibition }\end{array}$ & Observed & $\begin{array}{l}\text { Recovery } \\
\%\end{array}$ & $\begin{array}{l}\text { Expected } \\
\mu \mathrm{g} \text { ascorbic aci }\end{array}$ & $\begin{array}{l}\text { Observed } \\
d / g \text { DW }\end{array}$ & $\begin{array}{l}\text { Recovery } \\
\%\end{array}$ & $\begin{array}{l}\text { Expected } \\
\% \text { preservation }\end{array}$ & Observed & $\begin{array}{l}\text { Recovery } \\
\%\end{array}$ \\
\hline \multicolumn{10}{|c|}{ Extruded products } \\
\hline $10 \%$ & 10 & 34 & 341 & 120 & 144 & 120 & 6 & 4 & 67 \\
\hline $20 \%$ & 20 & 54 & 268 & 240 & 216 & 90 & 12 & 7 & 58 \\
\hline $30 \%$ & 30 & 66 & 219 & 360 & 256 & 71 & 18 & 6 & 33 \\
\hline \multicolumn{10}{|c|}{ Baked products } \\
\hline $10 \%$ & 10 & 12 & 125 & 120 & 46 & 38 & 6 & 6 & 102 \\
\hline $20 \%$ & 20 & 26 & 131 & 240 & 156 & 65 & 12 & 6 & 52 \\
\hline $30 \%$ & 30 & 33 & 110 & 360 & 182 & 51 & 18 & 9 & 52 \\
\hline
\end{tabular}

TPC, total phenolic content; TFC, total flavonoid content; PAC, proanthocyanidins content; DPPH, 2,2-diphenyl-1-picrylhydrazyl radical scavenging activity; FRAP, ferric reducing antioxidant power; BCLAS, $\beta$-carotene/linoleic acid system.

compared to the control (Fig. 1). The best results in extruded products were obtained for $30 \%$ AP incorporation resulting in 2.8 -fold, 4 -fold and 1.8 -fold increase in TPC, TFC and PAC, respectively. In baked products, the best results were obtained for $20 \%$ AP incorporation with an increase of 3.3-fold, 4-fold and 3.1fold for TPC, TFC and PAC, respectively.
The quantities expected of TPC, TFC and PAC for the respective percentage of AP incorporation observed and their respective recoveries are shown in Table 2. The expected results were calculated considering the TPC, TFC and PAC results obtained for AP reported by Reis et al. (2012) and the respective proportion of AP incorporated. Overall, the recoveries 

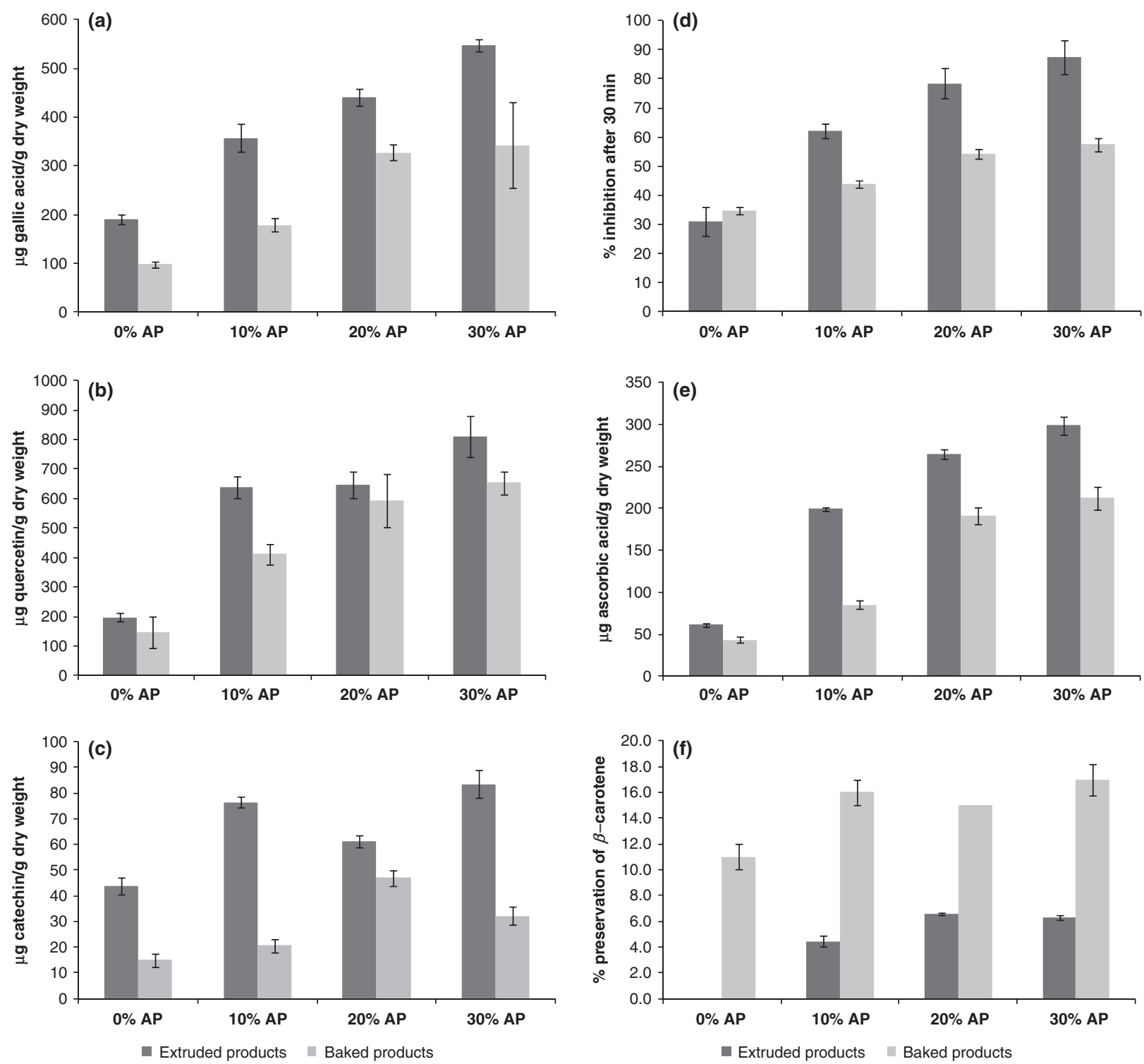

Figure 1 Results of (a) TPC, (b) TFC, (c) PAC, (d) DPPH radical scavenging activity, (e) FRAP and (f) $\beta$-carotene/linoleic acid system in AP incorporated extruded and baked products.

obtained showed a decreasing trend with the increase in AP incorporation. It is likely that polymerisation was promoted by heat treatment, as also seen in the previous section, which affected the extractability of such compounds, and the more phenolic compounds were incorporated, the higher was the polymerisation. Moreover, it was observed that TFC and PAC recoveries were lower than TPC recoveries for all the levels of incorporation. For $30 \%$ AP incorporation in extruded products, TPC recovery was double of TFC and PAC recoveries. This observation suggests that losses of flavonoids have occurred due to heat processing, and that other compounds were compensating for
TPC from the losses of flavonols and flavanols, probably thermally induced degradative products of phenolic origin. Rupasinghe et al. (2008) observed losses of flavonoids after the incorporation of $32 \%$ of apple skin powder in muffins, while the TPC was threefold higher than the control, and suggested that quercetin glycosides were partially converted to quercetin aglycone due to thermohydrolisis or deglycosilation.

\section{Antioxidant capacity evaluation}

The incorporation of AP significantly improved the antioxidant properties of the extruded and baked 
products when compared to the control (Fig. 1). Incorporation of $30 \%$ AP increased 2.8 -fold and 1.6-fold the DPPH radical scavenging activity, fivefold FRAP and sixfold and 1.5 -fold the preservation of $\beta$-carotene in a linoleic acid system in extruded and baked products, respectively.

The recoveries obtained for DPPH, up to $300 \%$ in extruded products (Table 2), together with the loss observed in phenolic compounds clearly show that other compounds than phenolics affected the DPPH radical scavenging activity. This is a strong evidence that these compounds are probably the well-known Maillard reaction products, already known as a result of the extrusion process (Singh et al., 2007) and often related with high scavenging activities (Amarowicz, 2009). A slight decrease in FRAP recoveries in extruded products was observed upon AP incorporation, and comparing with TPC results, it seems that FRAP is reflecting the antioxidant capacity from the recovered phenolic compounds. FRAP recoveries in baked products increased with the addition of AP but declined upon $30 \%$ AP incorporation, following the trend of TPC and PAC recoveries thus suggesting, as in extruded products, that the antioxidant activity measured by FRAP is influenced only by the recovered phenolic compounds. BCLAS recoveries in extruded products were the lowest; however, they were very close to the recoveries obtained for TFC and PAC. In baked products, BCLAS recoveries decreased up to $50 \%$ upon addition of $20 \%$ AP. A study by $\mathrm{Lu} \&$ Foo (2000) had shown that there is a direct correlation between the lower molecular weight procyanidins and quercetin glycosides and the excellent activity measured by the $\beta$-carotene/linoleic acid assay.

The incorporation of AP in extruded and baked products significantly increased the antioxidant activity measured by the DPPH radical scavenging activity, FRAP and $\beta$-carotene/linoleic acid system when compared to the control. However, these properties are not only influenced by the phenolic content but by new products generated by heat treatment, and from the high scavenging activity observed in extruded

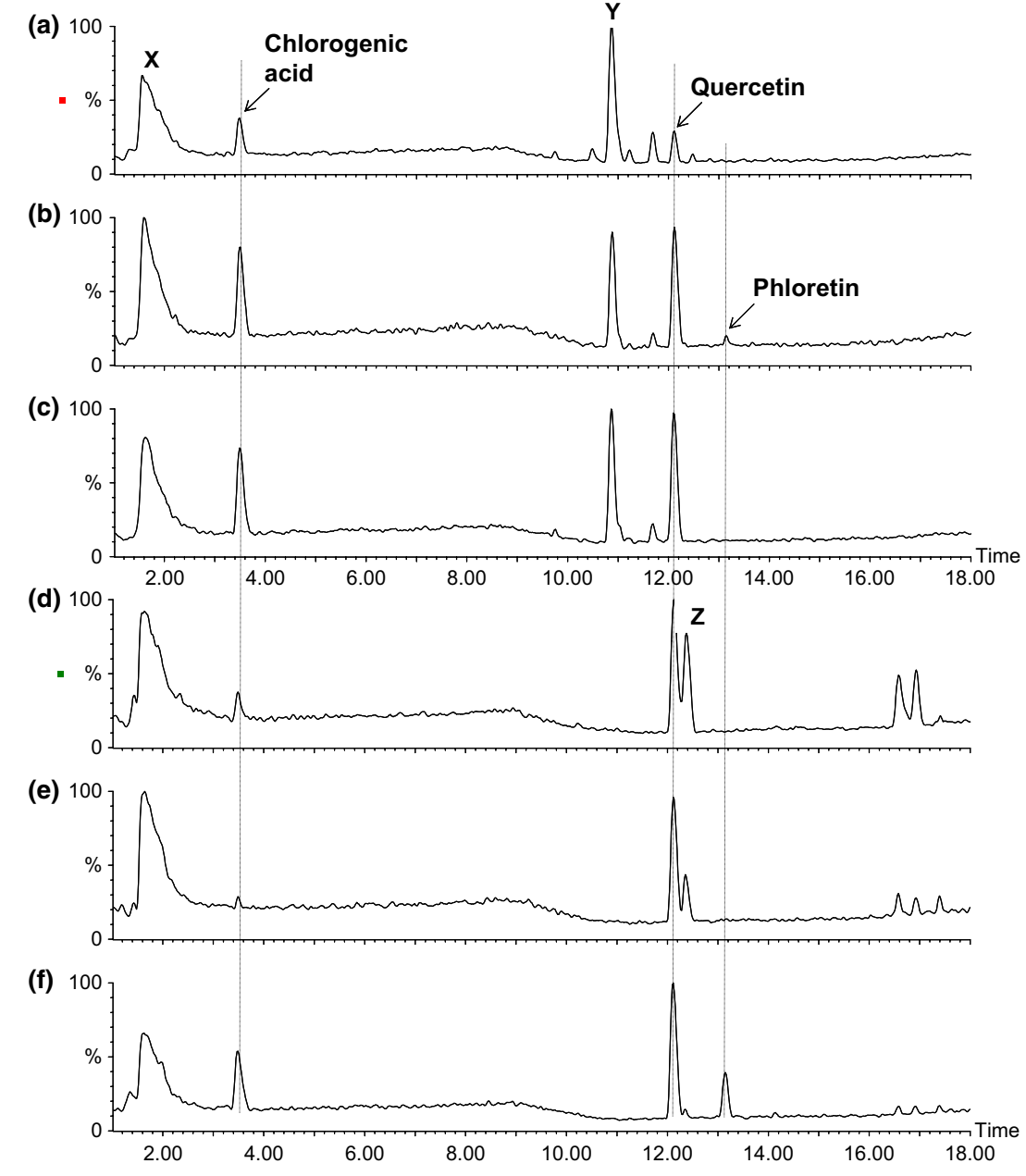

Figure 2 LC-MS chromatograms of (a) $10 \%$, (b) $20 \%$ and (c) $30 \%$ AP incorporation in extruded products and (d) $10 \%$, (e) $20 \%$ and (f) $30 \%$ AP incorporation in baked products. 
products, they are most likely to be Maillard reaction products (Amarowicz, 2009).

\section{Identification of phenolic compounds by LC-ESI/MS}

For all levels of AP incorporated in extruded and baked products, three polyphenols namely chlorogenic acid, quercetin and phloretin were identified (Fig. 2). With the increasing percentage of AP incorporation, the intensity of the chlorogenic acid and quercetin peaks also increased. Phloretin in extruded products declined with 30\% AP incorporation, but in baked products, it increased with the different levels of AP incorporation. There were three other major peaks, which could not be identified. One peak containing very polar compounds (peak X) most likely dominated by sugar molecules was present in all incorporated products. Unknown peak Y exclusively present in the extruded products with the exact mass of $188.0968 \mathrm{Da}$ gave a molecular formula of $\mathrm{C}_{9} \mathrm{H}_{16} \mathrm{O}_{4}$, while the unknown peak $\mathrm{Z}$ exclusively in the baked products with a molecular weight of $742 \mathrm{Da}$ was prominent at $10 \%$ AP incorporation and its intensity decreased with increasing levels of AP incorporation. These three unidentified peaks must have been originated from non-AP matrix or from the chemical interaction between the AP matrix and other ingredients used in extrusion and baking products. On close scrutiny of the LC-MS data, other polyphenols such as feruloylquinic acid [(M-H) ${ }^{-}$at $m / z$ 367.118], isorhamnetin $\left[(\mathrm{M}-\mathrm{H})^{-} \text {at } m / z \text { 315.067], phloridzin [(M-H }\right)^{-}$ at $m / z$ 435.178] and kaempferol $\left[(\mathrm{M}-\mathrm{H})^{-}\right.$at $m / z$ 285.06] were also observed (Fig. S1). With respect to the identified compounds in the AP of the same extract (Reis et al., 2012), in general the AP-incorporated extruded and baked products showed very little presence of the glycosidic forms of quercetin and phloretin, and all flavanols as illustrated by the extracted ion chromatogram for quercetin- $O$-glucoside $\left[(\mathrm{M}-\mathrm{H})^{-}\right.$at $m / z$ 463.09] in Fig. S1. This fact proves the loss of phenolic compounds observed in previous sections, and the intensities of chlorogenic acid, quercetin and phloretin explain the thermally induced degradative products of phenolic origin compensating that loss. Similar observation was made by Rupasinghe et al. (2008), as poor recovery of individual polyphenols was observed upon heat treatment, suggested that thermohydrolisis or deglycosylation of the glycosides of quercetin and phloretin could result in significant increase in quercetin and phloretin aglycones.

The LC-MS is in agreement with the results obtained for TFC, PAC and BCLAS described earlier. The poor presence of flavanols and quercetin glycosides was reflected in TFC, PAC and $\beta$-carotene/linoleic acid system recoveries.

\section{Conclusion}

Apple pomace from a chemical and nutritional point of view can be incorporated in extruded and baked products increasing the fibre content and the antioxidant properties of the final products. Acceptability studies should be performed in the extruded snacks and in the scones up to $20 \%$ addition of AP. Epidemiological studies would be required to prove that the fibre and antioxidant properties conferred by the AP incorporation can confer health promoting properties, thus proving AP as an ingredient for the development of functional foods.

\section{Acknowledgments}

The authors wish to acknowledge the Irish Department of Agriculture, Food and the Marine for their funding of this project (No 08RDTAFRC665) under the Food Institutional Research Measure (FIRM). The authors wish to thank Dr. Mahesh Gupta for the formulation of extruded snacks and Dr. Anastasia Ktenioudaki for the formulation of baked scones.

\section{References}

Ainsworth, P., Ibanoglu, S., Plunkett, A., Ibanoglu, E. \& Stojceska, V. (2007). Effect of brewers spent grain addition and screw speed on the selected physical and nutritional properties of an extruded snack. Journal of Food Engineering, 81, 702-709.

Ajila, C.M., Aalami, M., Leelavathi, K. \& Rao, U.J.S.P. (2010). Mango peel powder: a potential source of antioxidant and dietary fiber in macaroni preparations. Innovative Food Science \& Emerging Technologies, 11, 219-224.

Amarowicz, R. (2009). Antioxidant activity of Maillard reaction products. European Journal of Lipid Science and Technology, 111, 109-111.

Carson, K.J., Collins, J.L. \& Penfield, M.P. (1994). Unrefined, dried apple pomace as a potential food ingredient. Journal of Food Science, 59, 1213-1215.

Cetkovic, G., Canadanovic-Brunet, J., Djilas, S., Savatovic, S., Mandic, A. \& Tumbas, V. (2008). Assessment of polyphenolic content and in vitro antiradical characteristics of apple pomace. Food Chemistry, 109, 340-347.

Diñeiro García, Y., Valles, B.S. \& Picinelli Lobo, A. (2009). Phenolic and antioxidant composition of by-products from the cider industry: apple pomace. Food Chemistry, 117, 731-738.

Goldberg, I. (1994). Functional Foods. New York, London: Chapman \& Hall.

Lu, Y. \& Foo, L.Y. (2000). Antioxidant and radical scavenging activities of polyphenols from apple pomace. Food Chemistry, $\mathbf{6 8}$, $81-85$.

Onyango, C., Noetzold, H., Bley, T. \& Henle, T. (2004). Proximate composition and digestibility of fermented and extruded uji from maize-finger millet blend. LWT-Food science and Technology, 37, 827-832.

Reis, S.F., Rai, D.K. \& Abu-Ghannam, N. (2012). Water at room temperature as a solvent for the extraction of apple pomace phenolic compounds. Food Chemistry, 135, 1991-1998.

Rupasinghe, H.P.V., Wang, L., Huber, G.M. \& Pitts, N.L. (2008). Effect of baking on dietary fibre and phenolics of muffins incor- 
porated with apple skin powder. Food Chemistry, 107, 12171224.

Sanchez-Rabaneda, F., Jauregui, O., Lamuela-Raventos, R.M., Viladomat, F., Bastida, J. \& Codina, C. (2004). Qualitative analysis of phenolic compounds in apple pomace using liquid chromatography coupled to mass spectrometry in tandem mode. Rapid Communications in Mass Spectrometry, 18, 553-563.

Schieber, A., Hilt, P., Streker, P., Endres, H.-U., Rentschler, C. \& Carle, R. (2003). A new process for the combined recovery of pectin and phenolic compounds from apple pomace. Innovative Food Science \& Emerging Technologies, 4, 99-107.

Singh, S., Gamlath, S. \& Wakeling, L. (2007). Nutritional aspects of food extrusion: a review. International Journal of Food Science \& Technology, 42, 916-929.

Stojceska, V., Ainsworth, P., Plunkett, A., Ibanoglu, E. \& Ibanoglu, S. (2008a). Cauliflower by-products as a new source of dietary fibre, antioxidants and proteins in cereal based ready-to-eat expanded snacks. Journal of Food Engineering, 87, 554-563.

Stojceska, V., Ainsworth, P., Plunkett, A. \& Ibanoglu, S. (2008b). The recycling of brewer's processing by-product into ready-to-eat snacks using extrusion technology. Journal of Cereal Science, 47, 469-479.

Sudha, M.L., Baskaran, V. \& Leelavathi, K. (2007). Apple pomace as a source of dietary fiber and polyphenols and its effect on the rheological characteristics and cake making. Food Chemistry, 104, 686-692.

Wang, H.J. \& Thomas, R.L. (1989). Direct use of apple pomace in bakery products. Journal of Food Science, 54, 618-620.

\section{Supporting Information}

Additional Supporting Information may be found in the online version of this article:

Table S1. Quantities of TDF expected and observed in incorporated AP extruded and baked products and their respective recoveries.

Figure S1. Extracted ion chromatograms of feruloylquinic acid (368 Da), isorhamnetin $(316 \mathrm{Da})$, phloretin (274 Da), phloridzin (436 Da), kaempferol (286 Da) and quercetin- $O$-glucoside (464 Da) in (a) extruded and (b) baked products with $30 \%$ AP incorporation. 